\title{
Preoperative neutrophil-to-lymphocyte ratio is an independent prognostic marker in patients with laryngeal squamous cell carcinoma
}

\author{
Xiu-Ping Tu, Qian-Hui Qiu, Liang-Si Chen, Xiao-Ning Luo, Zhong-Ming Lu, Si-Yi Zhang ${ }^{*}$ and Shao-Hua Chen*
}

\begin{abstract}
Background: Neutrophil-lymphocyte ratio (NLR) has been shown to be associated with prognosis in various solid tumors. This study aimed to evaluate the prognostic role of NLR in patients with laryngeal squamous cell carcinoma (LSCC).

Methods: A total of 141 LSCC patients were retrospectively reviewed. Patients' demographics were analyzed along with clinical and pathologic data. The optimal cutoff value of NLR was determined using receiver operating characteristic (ROC) curve analysis. The impact of the NLR and other potential prognostic factors on disease-free survival (DFS) and overall survival (OS) was assessed using the Kaplan-Meier method and multivariate Cox regression analysis.

Results: The optimal cutoff value of the NLR was 2.17. In the NLR $\leq 2.17$ group, the 1-, 3-, and 5-year DFS rates were 88.2, 73.9 and $69.1 \%$, respectively, while in the NLR $>2.17$ group, the DFS rates were 83.0, 54.6 and $49.2 \%$, respectively. Correspondingly, the 1-, 3-, and 5-year OS rates were 98.9, 85.1 and $77.4 \%$ in the NLR $\leq 2.17$ group and 97.9, 63.8 and $53.3 \%$ in the NLR> 2.17 group, respectively. The multivariate Cox proportional hazard model analysis showed that NLR $>2.17$ was a prognostic factor for both DFS [hazard ratio (HR) $=1.869 ; 95 \%$ confidence interval $(C l) 1.078-3.243 ; P=0.026]$ and OS ( $H R=2.177 ; 95 \% \mathrm{Cl} 1.208-3.924 ; P=0.010)$.
\end{abstract}

Conclusion: Our results showed that elevated preoperative NLR was an independent predictor of poor prognosis for patients with LSCC after surgical resection.

Keywords: Laryngeal squamous cell carcinoma, Neutrophil-lymphocyte ratio, Prognostic marker

\section{Background}

Laryngeal squamous cell carcinoma (LSCC) is one of the most common head and neck malignancies that remain as significant cause of morbidity and mortality. Approximately 650,000 new cases and 350,000 cancer deaths attributed to this condition occur every year $[1,2]$. Treatment options in LSCC include surgery, radiotherapy, chemotherapy, or a combination of surgery, radio- and chemotherapy [3-7]. Despite improvements in treatment, an epidemiological survey indicated that the clinical outcome for LSCC has improved little in the past 20 years [8]. Therefore, it is of great significance to find novel and

\footnotetext{
*Correspondence: szhang555@hotmail.com; chenshaohua1168@163.com Department of Otorhinolaryngology, Guangdong General Hospital \& Guangdong Academy of Medical Sciences, Guangzhou, Guangdong 510080, P. R. China
}

effective biomarkers for prediction of LSCC patients with poor prognosis or at high risk of early recurrence.

Recently, there is increasing evidence that the host inflammatory response to cancer is associated with poor tumor-specific prognosis. Kawata et al. reported that lymphocyte infiltration around the tumor is associated with a better prognosis of HCC [9], whereas neutrophil in tumor stroma is associated with a poor prognosis [10]. Likewise, the neutrophil-to-lymphocyte ratio (NLR), a redictor of the patient's inflammatory status, has been hown to be an effective prognostic marker in many solid [11-17]. Kum et al. showed that neutrophil-tomphocyte ratio elevated in squamous cell carcinoma of larynx compared to benign and precancerous laryngeal lesions [18]. To our knowledge, the prognostic value of 
NLR in laryngeal squamous cell carcinoma has not been reported.

In this study, we evaluated the prognostic value of preoperative NLR in patients with LSCC after surgical resection.

\section{Methods \\ Patients}

Clinical data were collected from patients with LSCC who underwent surgical resection at the Department of Otorhinolaryngology, Guangdong General Hospital \& Guangdong Academy of Medical Sciences from January 2006 to August 2011. Clinical stage of laryngeal cancer was determined according to the AJCC- TNM stage ( $7^{\text {th }}$ ed, 2010) [19]. The selective criteria for the patients were as follows: (1) laryngeal squamous cell carcinoma confirmed by pathology, (2) older than 18 years of age; (3) complete clinical, laboratory, imaging, and follow-up data; (4) no evidence of sepsis [11]; (5) no hematological disorders or treatment that could result in an elevated NLR, for example, administration of hematopoietic agents such as granulocyte-colony stimulating factor (G-CSF) within 1 month before surgery; (6) no autoimmune disease or treatment with steroids; (7) no pre-operative treatments such as radiotherapy or chemotherapy; (8) patients were treated with curative intent. Routine blood tests were performed on the day before surgery. NLR was defined as the absolute neutrophil count divided by the absolute lymphocyte count. Patients were followed-up every 3 months for survival status, disease progression and time of death. The last follow-up was 30 September 2014. Disease-free survival (DFS) was recorded from the date of surgery to the date of recurrence, or last follow-up. Overall survival (OS) was recorded from the date of surgery to the date of death or last follow-up. This study was approved by the Research Ethics Committee of Guangdong General Hospital \& Guangdong Academy of Medical Sciences. All participants signed informed consent to participate in the study.

\section{Statistical analysis}

All statistical analyses were performed with SPSS version 19.0 software (Chicago, IL, USA). The chi-square test was used to compare categorical variables. Survival curves were plotted using the Kaplan-Meier method and compared using the log-rank test. Factors analyzed by univariate analysis with $P<0.05$ were included in multiple Cox proportional hazards model. $P<0.05$ was considered significant.

\section{Results}

\section{Demographic data}

A total of 141 patients were eligible for the study. The median age at diagnosis was 59 (range 36-87) years.
There were 137 men and 4 women. Eighty-three patients $(58.9 \%, 83 / 141)$ had a smoking index of 20 pack-year or more [20], and 24 patients $(17.0 \%, 24 / 141)$ had a drinking index of 1000 g-year or more [21]. Surgical procedures included total laryngectomy (43 cases, $30.5 \%$ ), partial laryngectomy (64 cases, $45.4 \%$ ), and $\mathrm{CO} 2$ laser surgery (34 cases, $24.1 \%)$. The locations of tumors included $80.2 \%(113 / 141)$ glottic, $17.0 \%(24 / 141)$ supraglottic and $2.8 \%(4 / 141)$ subglottic. Most of the patients were in the N0 stage ( $83.7 \%, 118 / 141)$, with 23 patients $(16.3 \%, 23 /$ $141)$ in the N1 to N3 stages. Eighty-six patients $(61.0 \%$, 86/141) were in T1 to T2 stages, and 55 patients $(39.0 \%$, $55 / 141$ ) were in the T3 to T4 stages. Details of features are shown in Table 1.

Table 1 Correlation between peripheral NLR and clinicopathologic variables of LSCC patients

\begin{tabular}{|c|c|c|c|c|}
\hline \multirow[b]{2}{*}{ Variables } & \multirow[b]{2}{*}{ Cases } & \multicolumn{2}{|l|}{ NLR } & \multirow[b]{2}{*}{ P } \\
\hline & & $N L R \leq 2.17$ & $N L R>2.17$ & \\
\hline \multicolumn{5}{|l|}{ Age (years) } \\
\hline$\leq 60$ & 74 & $48(64.9 \%)$ & $26(35.1 \%)$ & \\
\hline$>60$ & 67 & $46(68.7 \%)$ & $21(31.3 \%)$ & 0.633 \\
\hline \multicolumn{5}{|l|}{ Sex } \\
\hline Male & 137 & $90(65.7 \%)$ & 47 (34.3\%) & \\
\hline Female & 4 & $4(100.0 \%)$ & 0 & 0.151 \\
\hline \multicolumn{5}{|c|}{ Smoking history } \\
\hline Yes & 83 & $54(65.1 \%)$ & $29(34.9 \%)$ & \\
\hline No & 58 & $40(69.0 \%)$ & $18(31.0 \%)$ & 0.628 \\
\hline \multicolumn{5}{|c|}{ Drinking history } \\
\hline Yes & 24 & $15(62.5 \%)$ & 9 (37.5 \%) & \\
\hline No & 117 & $79(67.5 \%)$ & $38(32.5 \%)$ & 0.635 \\
\hline \multicolumn{5}{|l|}{ T classification } \\
\hline $\mathrm{T} 1-\mathrm{T} 2$ & 86 & $62(72.1 \%)$ & $24(27.9 \%)$ & \\
\hline T3-T4 & 55 & $32(58.2 \%)$ & $23(41.2 \%)$ & 0.087 \\
\hline \multicolumn{5}{|c|}{ Lymph node metastasis } \\
\hline Negative & 118 & $80(67.8 \%)$ & $38(32.2 \%)$ & \\
\hline Positive & 23 & $14(60.9 \%)$ & $9(39.1 \%)$ & 0.519 \\
\hline \multicolumn{5}{|c|}{ Histological grade } \\
\hline Well & 48 & $34(70.8 \%)$ & $14(29.2 \%)$ & \\
\hline Moderately & 73 & $48(65.8 \%)$ & $25(34.2 \%)$ & \\
\hline Poorly & 20 & $12(60.0 \%)$ & $8(40.0 \%)$ & 0.670 \\
\hline \multicolumn{5}{|l|}{ Primary location } \\
\hline Supraglottic & 24 & 15 (62.5 \%) & 9 (37.5 \%) & \\
\hline Glottic & 113 & 77 (68.1%) & 36 (31.9 \%) & 0.671 \\
\hline Subglottic & 4 & 2 (50.0 \%) & 2 (50.0 \%) & \\
\hline \multicolumn{5}{|l|}{ Clinical stage } \\
\hline$|-| \mid$ & 80 & $58(72.5 \%)$ & 22 (27.5 \%) & \\
\hline$\| I I-I V$ & 61 & 36 (59.0 \%) & 25 (41.0\%) & 0.092 \\
\hline
\end{tabular}

NLR neutrophil-to-lymphocyte ratio, LSCC Laryngeal squamous cell carcinoma 


\section{An optimal cutoff value for elevated NLR}

To avoid a predetermined cutoff point, the optimal cutoff score of preoperative NLR was defined by receiver operating characteristic (ROC) curve analysis. The cutoff value was that point closest to both maximum sensitivity and specificity. According to the ROC curve, the optimal cutoff value of preoperative NLR was 2.17. The area under the ROC curves was 0.614 with a $95 \%$ confidence interval $(95 \% \mathrm{CI})$ for the area between 0.515 and $0.713(P=0.024)$ (Fig. 1). Clinicopathological features according to NLR groups are summarized in Table 1.

\section{DFS and OS according to NLR status}

The 141 patients were divided into two groups: NLR $\leq$ 2.17 and NLR $>2.17$. The median patients' follow-up was 51 months (range: 5-102 months; mean \pm SD: 54.1 \pm 23.4 months). Ninety-six patients were alive at the end of follow-up and 52 patients developed recurrence 5-102 months after surgery (median 46 months). In the NLR $\leq$ 2.17 group, the 1-, 3-, and 5-year DFS rates were 88.2, 73.9 and $69.1 \%$, respectively, while in the NLR $>2.17$ group, the DFS rates were 83.0, 54.6 and $49.2 \%$, respectively (Fig. 2). Correspondingly, the 1-, 3-, and 5-year OS rates were $98.9,85.1$ and $77.4 \%$ in the NLR $\leq 2.17$ group and 97.9, 63.8 and $53.3 \%$ in the NLR $>2.17$ group, respectively (Fig. 3). Both DFS and OS of patients in the
$N L R \leq 2.17$ group were significantly longer than for patients in the NLR $>2.17$ group.

\section{Risk factors for prognosis of LSCC}

For all patients included in this study, the 1-, 3- and 5-year DFS rates were $86.5,67.5$ and $62.4 \%$, respectively. Rates for OS at the 1-, 3- and 5-year period were 98.6, 78.0 and $69.4 \%$, respectively. Univariate analysis revealed that advanced $\mathrm{T}$ classification ( $\mathrm{T} 3$ and $\mathrm{T} 4$ stages), Lymph node metastasis, primary location, NLR $>2.17$ and advanced clinic stage were associated with significantly poor DFS. Similarly, advanced T classification, Lymph node metastasis, primary location, NLR $>2.17$, poor histological grade and advanced clinical stage all predicted poor OS (Table 2).

Clinical stage was first excluded from the multivariable analyses because it was a comprehensive variable, and the other variables were entered stepwise into the multivariable Cox proportional hazard model by the forward conditional method. The analysis showed that NLR $>2.17(\mathrm{HR}=1.869$; $95 \%$ CI 1.078-3.243; $P=0.026$ ) and lymph node metastasis $(\mathrm{HR}=3.224 ; 95 \% \mathrm{CI} 1.751-5.937 ; P<0.001)$ were independent prognostic factors for DFS in patients with LSCC. NLR > $2.17(\mathrm{HR}=2.177 ; 95$ \% CI 1.208-3.924; $P=0.010)$, lymph node metastasis (HR $=2.968$; $95 \%$ CI 1.548-5.692; $P=0.001)$ and advanced T classification $(\mathrm{HR}=1.867 ; 95 \%$ CI $1.018-3.425 ; P=0.044$ ) were independent prognostic factors for OS in patients with LSCC (Table 3).

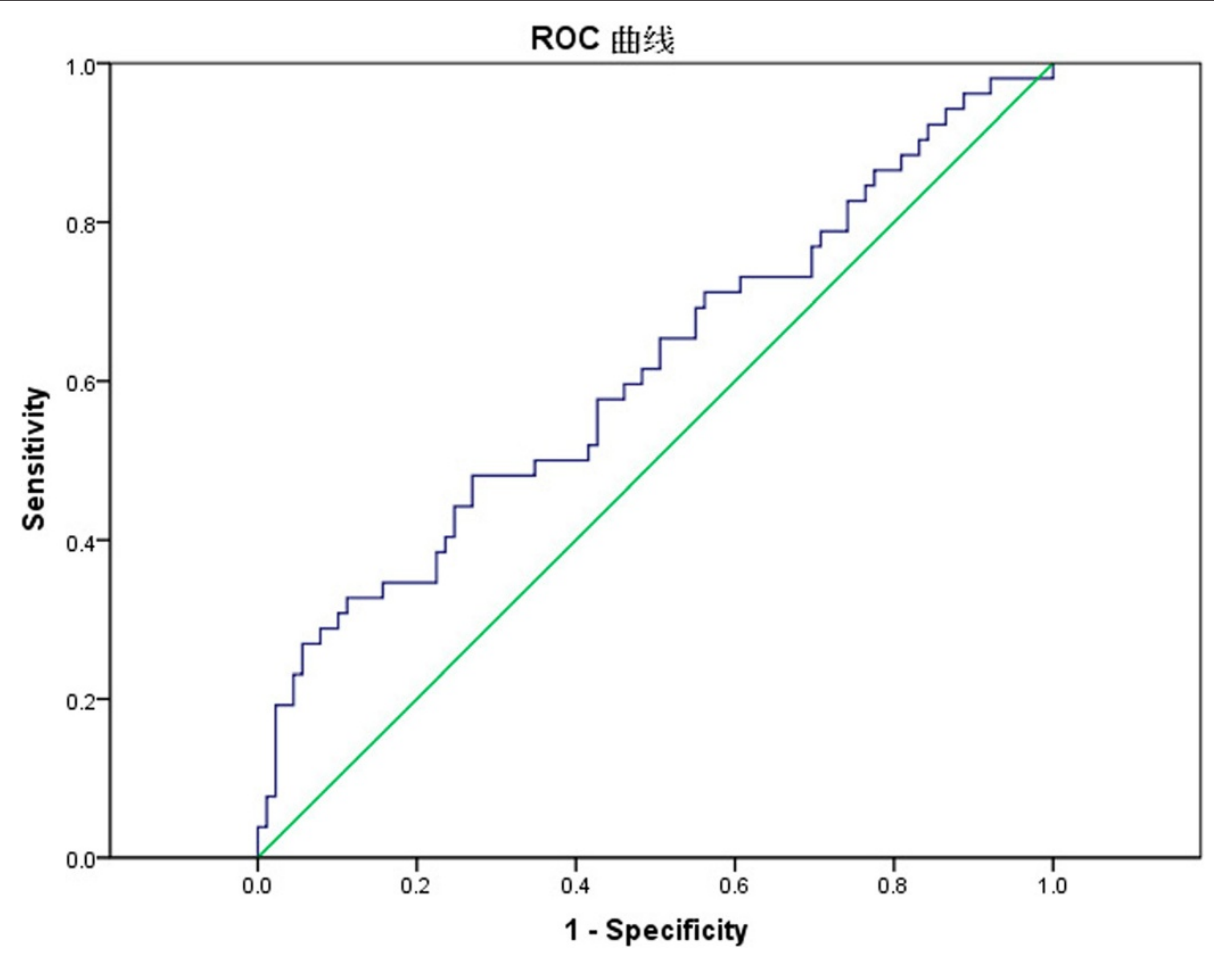

Fig. 1 Receiver operating characteristic curves of preoperative neutrophil-to-lymphocyte ratio (NLR) for predicting tumor recurrence in patients with Laryngeal squamous cell carcinoma (LSCC) after surgical resection 


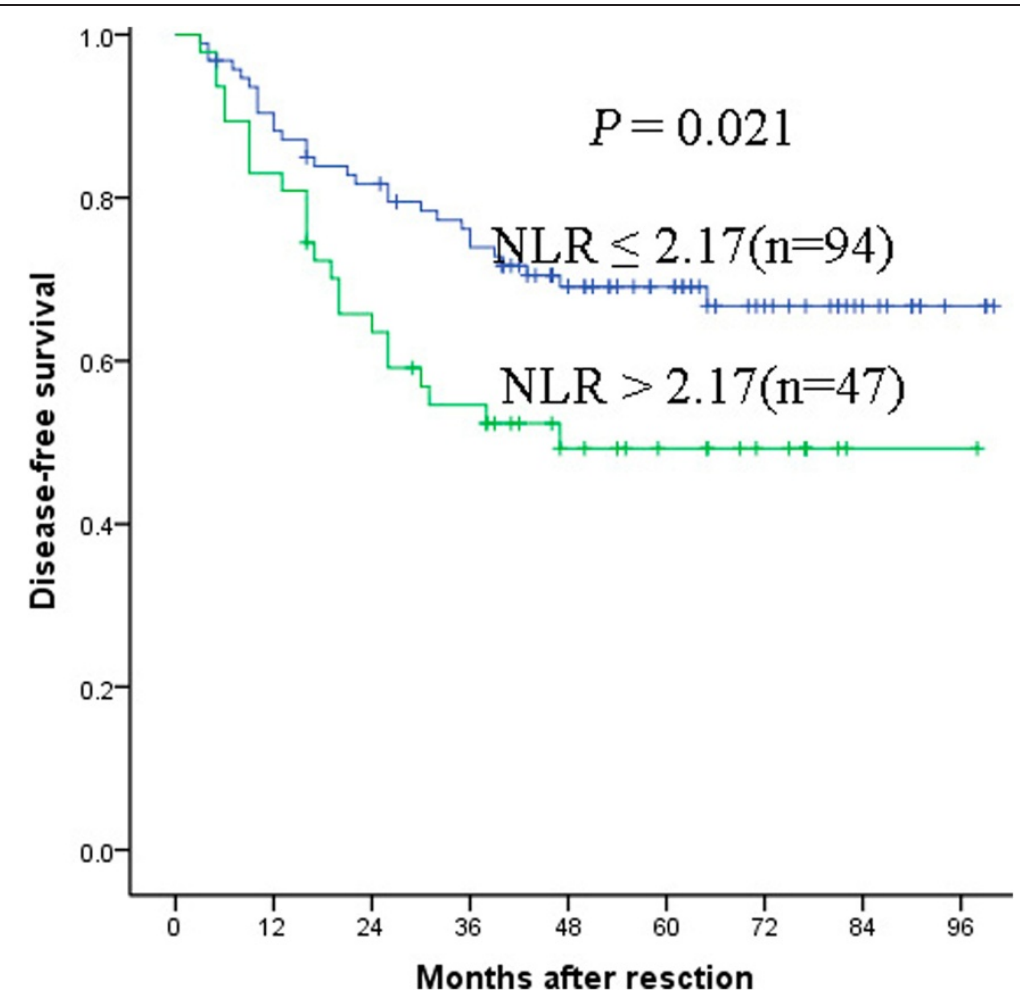

Fig. 2 Kaplan-Meier survival curves for DFS in patients with LSCC after surgical resection. Disease-free survival of patients with NLR $>2.17$ was shorter than those with $\mathrm{NLR} \leq 2.17$ ( $P=0.021$, log-rank)

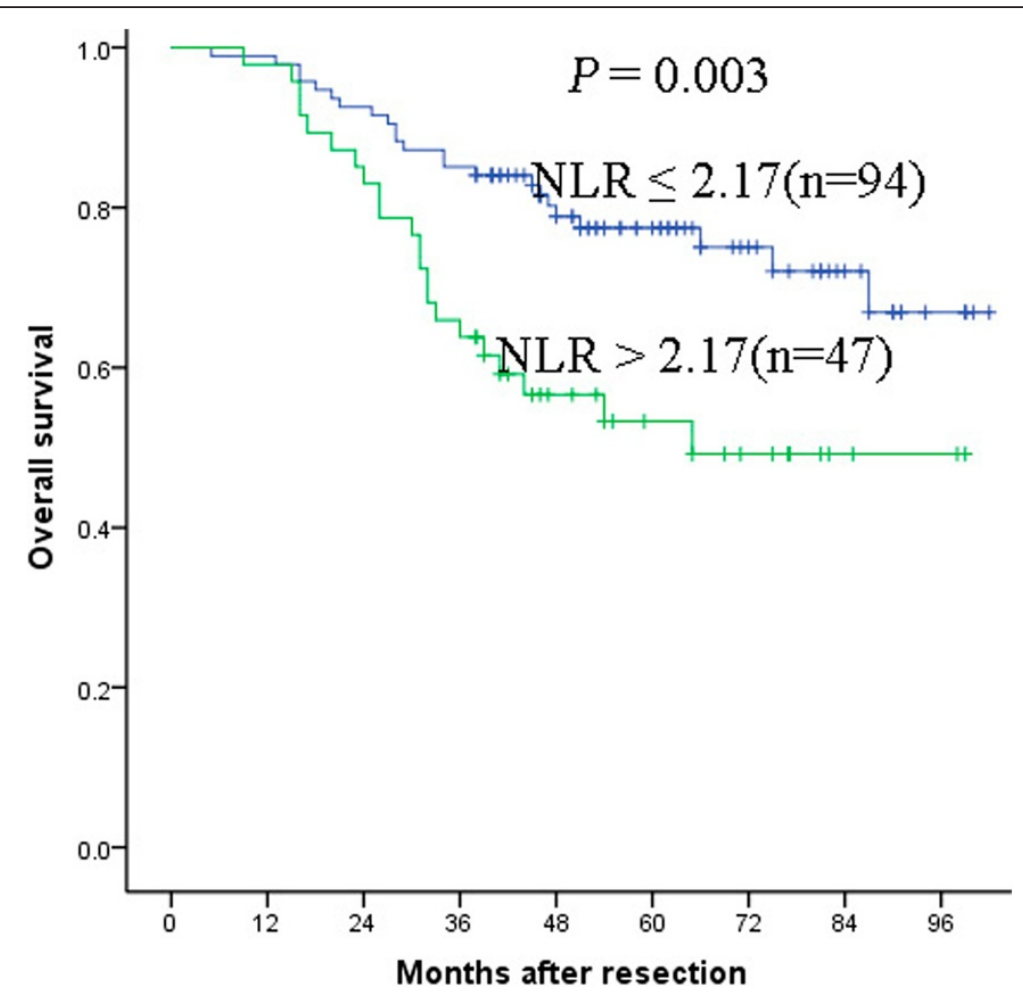

Fig. 3 Kaplan-Meier survival curves for OS in patients with LSCC after surgical resection. Overall survival of patients with NLR $>2.17$ was also shorter than those with NLR $\leq 2.17(P=0.003$, log-rank) 
Table 2 Prognostic factors for DFS and OS by univariate analysis

\begin{tabular}{|c|c|c|c|c|c|c|c|}
\hline \multirow[t]{2}{*}{ Variables } & \multirow[t]{2}{*}{$n$} & \multicolumn{3}{|l|}{ DFS } & \multicolumn{3}{|l|}{ OS } \\
\hline & & 3 -years & 5-years & P & 3 -years & 5 -years & P \\
\hline \multicolumn{8}{|l|}{ Age (years) } \\
\hline$\leq 60$ & 74 & $65.6 \%$ & $64.1 \%$ & & $75.7 \%$ & $72.7 \%$ & \\
\hline$>60$ & 67 & $69.4 \%$ & $60.7 \%$ & 0.980 & $80.6 \%$ & $66.9 \%$ & 0.41 \\
\hline \multicolumn{8}{|l|}{ Smoking history } \\
\hline Yes & 83 & $68.3 \%$ & $62.7 \%$ & & $74.7 \%$ & $67.2 \%$ & \\
\hline No & 58 & $66.3 \%$ & $62.2 \%$ & 0.886 & $82.8 \%$ & $73.0 \%$ & 0.464 \\
\hline \multicolumn{8}{|l|}{ Drinking history } \\
\hline Yes & 24 & $66.4 \%$ & $61.7 \%$ & & $66.7 \%$ & $61.1 \%$ & \\
\hline No & 117 & $67.7 \%$ & $62.6 \%$ & 0.845 & $80.3 \%$ & $71.1 \%$ & 0.414 \\
\hline \multicolumn{8}{|l|}{ T classification } \\
\hline $\mathrm{T} 1-\mathrm{T} 2$ & 86 & $74.3 \%$ & $68.6 \%$ & & $87.2 \%$ & $79.6 \%$ & \\
\hline $\mathrm{T} 3-\mathrm{T} 4$ & 55 & $56.1 \%$ & $51.8 \%$ & 0.039 & $63.6 \%$ & $53.7 \%$ & 0.003 \\
\hline \multicolumn{8}{|c|}{ Lymph node metastasis } \\
\hline Negative & 118 & $73.3 \%$ & $68.4 \%$ & & $83.9 \%$ & $75.9 \%$ & \\
\hline Positive & 23 & $35.5 \%$ & $28.4 \%$ & $<0.001$ & $47.8 \%$ & $35.9 \%$ & $<0.001$ \\
\hline \multicolumn{8}{|l|}{ NLR } \\
\hline$\leq 2.17$ & 94 & $73.9 \%$ & $69.1 \%$ & & $85.1 \%$ & $77.4 \%$ & \\
\hline$>2.17$ & 47 & $54.6 \%$ & $49.2 \%$ & 0.021 & $63.8 \%$ & $53.3 \%$ & 0.003 \\
\hline \multicolumn{8}{|c|}{ Histological grade } \\
\hline Well & 48 & $83.0 \%$ & $70.5 \%$ & & $93.7 \%$ & $80.4 \%$ & \\
\hline Moderately & 73 & $59.6 \%$ & $59.6 \%$ & & $74.0 \%$ & $67.4 \%$ & \\
\hline Poorly & 20 & $59.6 \%$ & $53.6 \%$ & 0.169 & $55.0 \%$ & $49.5 \%$ & 0.043 \\
\hline \multicolumn{8}{|l|}{ Primary location } \\
\hline Supraglottic & 24 & $55.9 \%$ & $43.1 \%$ & & $58.3 \%$ & $37.4 \%$ & \\
\hline Glottic & 113 & $69.5 \%$ & $66.6 \%$ & & $82.3 \%$ & $77.4 \%$ & \\
\hline Subglottic & 4 & $75.0 \%$ & $50.0 \%$ & 0.165 & $75.0 \%$ & $50.0 \%$ & 0.001 \\
\hline \multicolumn{8}{|l|}{ Clinical stage } \\
\hline$|-| \mid$ & 80 & $74.9 \%$ & $70.3 \%$ & & $87.5 \%$ & $81.1 \%$ & \\
\hline III-IV & 61 & $57.2 \%$ & $51.4 \%$ & 0.022 & $65.6 \%$ & $54.5 \%$ & 0.004 \\
\hline
\end{tabular}

DFS disease-free survival, OS overall survival. Other abbreviations are the same as in Table 1

\section{Discussion}

Recent evidence suggests that the development and progression of cancers is closely associated with inflammation and immunity status. The neutrophil-to-lymphocyte ratio is a simple and effective marker of inflammation and immunity. It reflects the patient's inflammatory and immunity status. NLR has been shown to be a valuable prognostic marker in patients with some solid tumors in many studies, such as hepatocellular carcinoma [11, 22], gastric cancer [23], soft tissue sarcoma [24], esophageal cancer $[17,25]$ and breast cancer [26, 27]. However, the cutoff value of NLR is not consistent. In most studies,

Table 3 Prognostic factors for DFS and OS as determined by multivariate Cox proportional hazards regression model

\begin{tabular}{|c|c|c|c|c|c|c|}
\hline \multirow[t]{2}{*}{ Variables } & \multicolumn{3}{|l|}{ DFS } & \multicolumn{3}{|l|}{ OS } \\
\hline & $\mathrm{HR}$ & $95 \% \mathrm{Cl}$ & $P$ & $\mathrm{HR}$ & $95 \% \mathrm{Cl}$ & $P$ \\
\hline T classification & & & & 1.867 & $1.018-3.425$ & 0.044 \\
\hline Lymph node metastasis & 3.224 & $1.751-5.937$ & $<0.001$ & 2.968 & $1.548-5.692$ & 0.001 \\
\hline NLR & 1.869 & $1.078-3.243$ & 0.026 & 2.177 & $1.208-3.924$ & 0.010 \\
\hline
\end{tabular}

$H R$ hazard ratio, $\mathrm{Cl}$ confidence interval. Other abbreviations are the same as in Tables 1 and 2 
the cutoff value of NLR has been empirically set. To avoid a predetermined cutoff point, we determined that the optimal cutoff value of NLR was 2.17 for predicting prognosis of patients with LSCC by using ROC curve analysis in this study. To the best of our knowledge, this study is the first to evaluate the prognostic role of NLR in patients with LSCC.

We found that patients with elevated NLR $(>2.17)$ had significantly shorter DFS and OS than those with low NLR $(\leq 2.17)$ (Figs. 2 and 3, Table 2). The multiple Cox proportional hazard regression analysis showed that NLR $>2.17$ was an independent prognostic factor of short DFS and OS in patients with LSCC. The relationship between a high pretreatment NLR and poor prognosis has also been observed in patients with other squamous cell carcinoma $[17,25,28,29]$. Recently, Kum et al. demonstrated that NLR was a useful inflammatory marker to differentiate LSCC patients from benign laryngeal lesion (BLL) and precancerous laryngeal lesion (PLL) patients [18].

Although the association between elevated NLR and poor prognosis has been confirmed by many studies, the underlying mechanisms have not yet been fully elucidated [11-16]. One possible explanation is that a relatively increased number of circulating neutrophils produced and secreted angiogenesis-regulating growth factors, chemokines and proteases (e.g., vascular endothelial growth factor (VEGF) [30], interleukin-8 (IL-8) [31], intercellular adhesion molecule 1 [32] and matrix metalloproteinase (MMP)) [33] which may promote tumor growth and metastasis resulting in poor prognosis. Another explanation is that the host immune response to tumors is lymphocyte dependent. Patients with elevated NLR usually have relative lymphocytopenia, and this may reflect a deficient immune response to tumors mediated by $\mathrm{CD} 4^{+}$T-helper and cytotoxic $\mathrm{CD} 8^{+}$ cell [34].

\section{Conclusions}

This study demonstrated that elevated preoperative NLR was an independent prognostic marker of poor DFS and OS in patients with LSCC. NLR is a simple, easily accessible indicator for identifying LSCC patients following surgical resection. It might help clinicians support intensive followup surveillance and adopt personalized adjuvant therapies for patients with LSCC who were at high risk for recurrence after surgical resection. It is noted that this study is limited by its retrospective nature and the relatively small size in a single-center. Further multicenter, large prospective studies are needed to confirm the findings.

\section{Abbreviations}

NLR: Neutrophil-lymphocyte ratio; LSCC: Laryngeal squamous cell carcinoma; ROC: Receive operating characteristic; DFS: Disease-free survival; OS: Overall survival; HR: Hazard ratio; Cl: Confidence interval; G-CSF: Granulocyte-colony stimulating factor; BLL: Benign laryngeal lesion; PLL: Precancerous laryngeal lesion; VEGF: Vascular endothelial growth factor; IL-8: Interleukin-8;

MMP: Matrix metalloproteinase.
Competing interests

The authors declare that they have no competing interests.

\section{Authors' contributions}

XPT, SYZ and SHC were the main authors of the manuscript. They were involved in the conception, design and coordination of the study as well as in data analysis, interpretation of results and drafting the manuscript. SHC and SYZ were in charge of all experimental procedures. QHQ, LSC, XNL and ZML participated in the experimental procedures and revised critically the content of the manuscript. All authors contributed to the interpretation of data and critically revised the manuscript. All authors read and approved the final manuscript.

\section{Acknowledgments}

This study was supported by grants from the development and popularization applications of special provincial finance technology (NO. Z012013104). The funders had no role in study design, data collection and analysis, decision to publish, or preparation of the manuscript.

Received: 21 January 2015 Accepted: 8 October 2015

Published online: 20 October 2015

\section{References}

1. Farhadieh RD, Rees CG, Yang JL, Salardini A, Russell P, Smee R. Radiotherapy in larynx squamous cell carcinoma is not associated with an increased diagnosis of second primary tumours. Clin Oncol (R Coll Radiol). 2009;21(4):315-9.

2. Parkin DM, Bray F, Ferlay J, Pisani P. Global cancer statistics, 2002. CA Cancer J Clin. 2005:55(2):74-108.

3. Tai $P, Y u$ E, Shiels $R$, Tonita J. Long-term survival rates of laryngeal cancer patients treated by radiation and surgery, radiation alone, and surgery alone: studied by lognormal and Kaplan-Meier survival methods. BMC Cancer. 2005;5:13.

4. Ghaffar S, Akhtar S, Ikram M, Imam SZ, Sepah YJ. Comparison of different treatment modalities in advanced laryngeal hypopharyngeal squamous cell carcinoma. J Coll Physicians Surg Pak. 2010;20(3):171-4.

5. Varghese BT, Sebastian P, Mathew A. Treatment outcome in patients undergoing surgery for carcinoma larynx and hypopharynx: a follow-up study. Acta Otolaryngol. 2009;129(12):1480-5.

6. Mahler V, Boysen M, Brøndbo K. Radiotherapy or CO(2) laser surgery as treatment of $\mathrm{T}(1 \mathrm{a})$ glottic carcinoma? Eur Arch Otorhinolaryngol. 2010;267(5):743-50.

7. Bajaj Y, Shayah A, Sethi N, Harris AT, Bhatti I, Awobem A, et al. Clinical outcomes of total laryngectomy for laryngeal carcinoma. Kathmandu Univ Med J (KUMJ). 2009;7(27):258-62.

8. Yilmaz M, Karatas OF, Yuceturk B, Dag H, Yener M, Ozen M. Alpha-Bcrystallin expression in human laryngeal squamous cell carcinoma tissues. Head Neck. 2014. doi: 10.1002/hed.23746.

9. Kawata A, Une Y, Hosokawa M, Uchino J, Kobayashi H. Tumorinfiltrating lymphocytes and prognosis of hepatocellular carcinoma. Jpn J Clin Oncol. 1992:22:256-63.

10. Yamashita J, Ogawa M, Shirakusa T. Free-from neutrophil elastase is an independent marker predicting recurrence in primary breast cancer. J Leukoc Biol. 1995;57:375-8.

11. Fu SJ, Shen SL, Li SQ, Hua YP, Hu WJ, Liang LJ, et al. Prognostic value of preoperative peripheral neutrophil-to-lymphocyte ratio in patients with HBV-associated hepatocellular carcinoma after radical hepatectomy. Med Oncol. 2013;30(4):721.

12. Kang MH, Go SI, Song HN, Lee A, Kim SH, Kang JH, et al. The prognostic impact of the neutrophil-to-lymphocyte ratio in patients with small-cell lung cancer. Br J Cancer. 2014;111(3):452-60.

13. MCNamara MG, Templeton AJ, Maganti M, Walter T, Horgan AM, McKeever $L$, et al. Neutrophil/lymphocyte ratio as a prognostic factor in biliary tract cancer. Eur J Cancer. 2014;50(9):1581-9.

14. Hamed MO, Roberts KJ, Smith AM, Morris Stiff G. Elevated pre-operative neutrophil to lymphocyte ratio predicts disease free survival following pancreatic resection for periampullary carcinomas. Pancreatology. 2013;13(5):534-8.

15. Zhang $Y$, Wang L, Liu Y, Wang S, Shang P, Gao Y, et al. Preoperative neutrophil-lymphocyte ratio before platelet-lymphocyte ratio predicts 
clinical outcome in patients with cervical cancer treated with initial radical surgery. Int J Gynecol Cancer. 2014;24(7):1319-25.

16. Hermanns T, Bhindi B, Wei Y, Yu J, Noon AP, Richard PO, et al. Pre-treatment neutrophil-to-lymphocyte ratio as predictor of adverse outcomes in patients undergoing radical cystectomy for urothelial carcinoma of the bladder. $\mathrm{Br} J$ Cancer. 2014;111(3):444-51.

17. Feng JF, Huang $Y$, Chen QX. Preoperative platelet lymphocyte ratio (PLR) is superior to neutrophil lymphocyte ratio (NLR) as a predictive factor in patients with esophageal squamous cell carcinoma. World J Surg Oncol. 2014;12:58.

18. Kum RO, Ozcan M, Baklaci D, Kum NY, Yilmaz YF, Gungor V, et al. Elevated neutrophil-to-lymphocyte ratio in squamous cell carcinoma of larynx compared to benign and precancerous laryngeal lesions. Asian Pac J Cancer Prev. 2014;15(17):7351-5.

19. Edge SB. Cancer staging manual[M]. 7th ed. New York: Springer; 2010. p. 57-67.

20. Zhang SY, Lu ZM, Luo XN, Chen LS, Ge PJ, Song XH, et al. Retrospective analysis of prognostic factors in 205 patients with laryngeal squamous cell carcinoma who underwent surgical treatment. PLoS One. 2013;8(4), e60157. doi:10.1371/journal.pone.0060157.

21. Imai R, Takenaka Y, Yasui T, Nakahara S, Yamamoto Y, Hanamoto A, et al. Prognostic significance of serum squamous cell carcinoma antigen in patients with head and neck cancer. Acta Otolaryngol. 2015;135(3):295-301.

22. Mano Y, Shirabe K, Yamashita Y, Harimoto N, Tsujita E, Takeishi K, et al. Preoperative neutrophil-to- lymphocyte ratio is a predictor of survival after hepatectomy for hepatocellular carcinoma: a retrospective analysis. Ann Surg. 2013;258(2):301-5.

23. Graziosi L, Marino E, De Angelis V, Rebonato A, Cavazzoni E, Donini A. Prognostic value of preoperative neutrophils to lymphocytes ratio in patients resected for gastric cancer. Am J Surg. 2014. doi:10.1016/j.amjsurg.2014.06.014.

24. Idowu OK, Ding Q, Taktak AF, Chandrasekar CR, Yin Q. Clinical implication of pretreatment neutrophil to lymphocyte ratio in soft tissue sarcoma. Biomarkers. 2012;17(6):539-44.

25. Sharaiha RZ, Halazun KJ, Mirza F, Port JL, Lee PC, Neuqut Al, et al. Elevated preoperative neutrophil: lymphocyte ratio as a predictor of postoperative disease recurrence in esophageal cancer. Ann Surg Oncol. 2011;18(12):3362-9.

26. Eryilmaz MK, Mutlu H, Salim DK, Musri FY, Tural D, Coskun HS. The neutrophil to lymphocyte ratio has a high negative predictive value for pathologic complete response in locally advanced breast cancer patients receiving neoadjuvant chemotherapy. Asian Pac J Cancer Prev. 2014;15(18):7737-40.

27. Yao M, Liu Y, Jin H, Liu X, Lv K, Wei H, et al. Prognostic value of preoperative inflammatory markers in Chinese patients with breast cancer. Onco Targets Ther. 2014;7:1743-52.

28. Perisanidis C, Kornek G, Pöschl PW, Holzinger D, Pirklbauer K, Schopper C, et al. High neutrophil-to-lymphocyte ratio is an independent marker of poor disease-specific survival in patients with oral cancer. Med Oncol. 2013;30(1):334.

29. Rassouli A, Saliba J, Castano R, Hier M, Zeitouni AG. Systemic inflammatory markers as independent prognosticators of head and neck squamous cell carcinoma. Head Neck. 2015;37(1):103-10.

30. Fondevila C, Metges JP, Fuster J, Grau JJ, Palacín A, Castells A, et al. p53 and VEGF expression are independent predictors of tumour recurrence and survival following curative resection of gastric cancer. Br J Cancer. 2004;90(1):206-15.

31. Schaider H, Oka M, Bogenrieder T, Nesbit M, Satyamoorthy K, Berking C, et al. Differential response of primary and metastatic melanomas to neutrophils attracted by IL-8. Int J Cancer. 2003;103(3):335-43.

32. Liu S, Li N, Yu X, Xiao X, Cheng K, Hu J, et al. Expression of intercellular adhesion molecule 1 by hepatocellular carcinoma stem cells and circulating tumor cells. Gastroenterology. 2013;144(5):1031-41.

33. Sivaramakrishnan V, Niranjali Devaraj S. Morin regulates the expression of NF-KB-p65, COX-2 and matrix metalloproteinases in diethylnitrosamine induced rat hepatocellular carcinoma. Chem Biol Interact. 2009;180(3):353-9.

34. Ohtani H. Focus on TILs: prognostic significance of tumor infiltrating lymphocytes in human colorectal cancer. Cancer Immun. 2007;7:4.

\section{Submit your next manuscript to BioMed Central and take full advantage of:}

- Convenient online submission

- Thorough peer review

- No space constraints or color figure charges

- Immediate publication on acceptance

- Inclusion in PubMed, CAS, Scopus and Google Scholar

- Research which is freely available for redistribution

Submit your manuscript at www.biomedcentral.com/submit 